\title{
Research on Design Aesthetics and Cultural Connotation of Gold and Silver Interlocking Buckle in the Ming Dynasty
}

Xiao'ang $\mathrm{Hao}^{1, * *}$ Zhihong Yin ${ }^{1}$

${ }^{1}$ Wuhan Textile University, Wuhan, Hubei 430073, China

${ }^{* * *}$ Corresponding author. Email: 1123613037@qq.com

\begin{abstract}
The gold and silver interlocking buckle is a unique accessory commonly seen in women's clothing in Ming Dynasty. It is composed of a button loop with a bayonet, a flat spherical button and two keepers. This article organizes and summarizes the types of gold and silver interlocking buckles in the Ming Dynasty; analyzes the ingenious structure of this kind of interlocking buckle and the unique design aesthetics reflected in the shapes; and expounds the rich cultural connotation of gold and silver interlocking buckle: it is an intuitive expression of the aesthetic concepts of the Ming Dynasty society, an indirect proof of the strong trend of the Ming Dynasty society's conspicuous consumption in the context of economic prosperity, and a material medium for the Ming Dynasty women to practice the concept of covering the body. These rich cultural connotation and aesthetic value are the inspiration source and cultural cornerstone of today's clothing design.
\end{abstract}

Keywords: Ming Dynasty, gold and silver interlocking buckle, Design Aesthetic, conspicuous consumption,

covering the body

\section{INTRODUCTION}

After the Song and Yuan Dynasties, the craftsmanship of Gold and Silver Ware have reached a new peak in the Ming Dynasty, and the types and styles of Gold and Silver Ware also have been enriched and developed. Among them, the gold and silver interlocking buckles appearing in Ming Dynasty women's clothes are noteworthy examples. This kind of interlocking buckle was generally used for fixing the collar or the placket. Each pair of buckles consist of a button loop, a button, and two keepers. At present, academic researches on gold and silver interlocking buckles has begun to take shape. For example, Yang Zhishui classified this kind of interlocking buckle as jewelry and studied the pattern of the theme of "Butterflies and Flower"[1]; Wang Jiaqi studied this kind of interlocking buckle from the aspects of structural evolution, application methods and visual design[2]; Chen Fang mainly discussed the origin of this kind of interlocking buckle[3]. These studies allow

*Project: This paper is one of the phased achievements of the 2018 Ministry of Education project: "Study on Women's Costumes and Social Fashion in Classical Literature in the Ming and Qing Dynasties" (Project No.: 18YJA760073)

2019 Wuhan Textile University project: "Research on Chinese Han Nationality Female's Garment Structure in the Ming Dynasty" (Reference No.: Wu Fang Da Yan [2013] No. 11). us to appreciate the unique style of gold and silver interlocking buckles in the Ming Dynasty, and this article will make an in-depth discussion on the design of gold and silver interlocking buckles in the Ming Dynasty and the culture of the times, and explore the unique design aesthetics contained in the gold and silver interlocking buckle and the cultural connotation of the times behind it.

\section{DESIGN AESTHETICS OF GOLD AND} SILVER INTERLOCKING BUCKLE IN MING DYNASTY

\section{A. The beauty of structure - clever and practical structural design}

The button loop and the button in the gold and silver interlocking buckle form an open-close component which has the function of opening and closing the buckle, and the two keepers are used to fix the button loop and the button. The beauty of structure of the Ming Dynasty gold and silver interlocking buckle is mainly reflected in the structural design of the openclose component.

The "opposite" and "unified" relationship between the structure and material of the buckle's open-close component can best show the beauty of its structure. 
The open-close component of the fabric braid button use the suppleness of the fabric to achieve the locking and releasing of the button loop to the button, so as to achieve the purpose of convenient opening and closing. The fabric braid buckles had appeared in the Song costumes, as shown in "Fig. 1"; the Yuan Dynasty fabric braid buckles had shown a certain decorative effect, as shown in "Fig. 2"; and in the Ming Dynasty, gold and silver interlocking buckles appeared for the first time. From fabric braid buckle to gold and silver interlocking buckle, how to deal with the "opposite" relationship between the "stiffness" of gold and silver materials and the "suppleness" required by the button loop became a key issue to be solved by artisans in the Ming Dynasty. Judging the unearthed objects, the Ming Dynasty artisans used the bayonet on the button loop to realize the "unified" relationship between the structure and material of the gold and silver interlocking buckle open-close component. In the Ming Dynasty gold and silver interlocking buckle, the two pieces of metal extending inward from the inner edge of the button loop compose the bayonet. In order to ensure that the button can pass through the gap in the middle of the bayonet, the button is also changed from a spherical shape to a flat spherical shape. "Fig. 3" shows an Ming Dynasty gold and silver buckle in the open state. Therefore, when closing the buckle, simply twist the button to feed it into the button loop, and then twist it again to make the button firmly locked by the bayonet on the button loop. This structure greatly improves the applicability of the gold and silver interlocking buckle.

The appearance of the interlocking buckle with this open-close structure promoted the emergence and popularity of the mandarin collar and the Chinese style jacket with buttons down the front, and also laid the

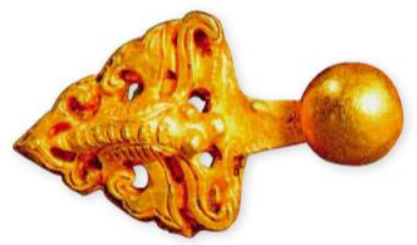

Fig. 3. A pair of Ming Dynasty gold and silver buckle in the open state.

\section{B. The beauty of form-highlight the decorative function}

The gold and silvers interlocking buckles of the Ming Dynasty pursue a balanced beauty of bilateral symmetry in the overall structure, but in the aspect of shapes they show the characteristics of exquisite elegance and rich change. These buckles of the Ming Dynasty have various form themes, such as "蝶采花 (Butterflies and flower)" "云托月(Clouds and Moon)" " 双银锭(Double Silver ingots)" and so on, and the typical themes of Ming Dynasty gold and silver interlocking buckles' form are presented in "Table I". All the foundation for the subsequent use of a large number of Chinese knot buckles. What's more, the structure design of this kind of buckle shows that the Ming Dynasty craftsmen's ingenuity in the design of the structure of the utensils, and also reflects their profound ability to control the gold and silver materials. And the existence of these excellent craftsmen in turn confirms the rationality and historical inevitability of the Ming Dynasty gold and silver jewelry becoming the pinnacle of traditional Chinese jewelry.

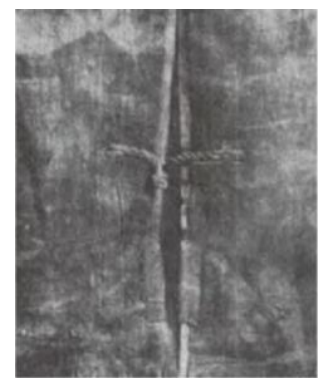

Fig. 1. The fabric braid buckle in the Song Dynasty clothing.
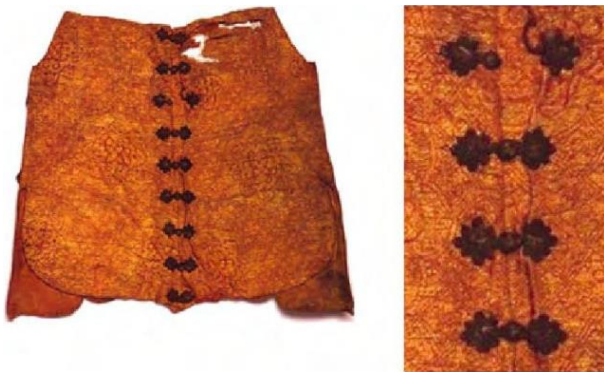

Fig. 2. The fabric braid buckles in the Yuan Dynasty clothing.

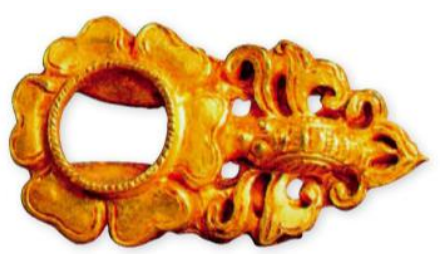

interlocking buckles show the formal beauty of the high integration of shape and structure which makes the functional components of the interlocking buckles are concealed and highlights the decorative effect of gold and silver interlocking buckles to the greatest extent. 
TABLE I. TYPICAL THEMES OF MING DYNASTY GOLD AND SILVER INTERLOCKING BUCKLES’ FORM

\begin{tabular}{|c|c|c|c|c|c|c|}
\hline Themes & $\begin{array}{c}\text { Butterflies and } \\
\text { Flower }\end{array}$ & Clouds and Moon & Double Silver ingots & Character & Tong Zi Peng Hua & Fish and Lotus \\
\hline Examples & & & & & & \\
\hline
\end{tabular}

The concealment of the functional components of the gold and silver interlocking buckles is divided into two aspects, including the concealment of the openclose component and the keepers. Among all the shape designs, the most typical example is the design of the form of the "蝶采花(Butterflies and Flower)" theme, and the following is the detailed analysis on the shape design of the theme of "Butterflies and Flower". The first aspect is the concealment of the open-close component which is composed of a button loop and a button. In the gold and silver interlocking buckles of the "蝶采花(Butterflies and Flower)" theme, the button loop and the button make up a complete flower in bloom when they are closed; and when they are opened, the button becomes the center of the flower, and the button loop becomes the petal. The second aspect is the concealment of the keepers. The two keepers of the gold and silver interlocking buckle become two lifelike butterflies flying around the "flower", and the holes on the keepers used for threading also become patterns on the wings of the butterflies. The shapes of this theme is in line with people's cognition of natural things, but it also breaks the laws of natural world. The design activities of the artisans of the Ming Dynasty made the forms in natural world appear in the ornaments, which fully demonstrated their great association and imagination ability. In addition, the shape of the theme of "Butterflies and Flower" also appeared in other gold and silver ornaments in Ming Dynasty, which shows that the Ming people love it very much, and also proves that the design of this theme is so exquisite.

The concept of the form design of the Ming Dynasty gold and silver interlocking buckles is to greatly enhance its decorative nature on the basis of retaining the opening and closing function of buckles. It is also under the support of this design concept that gold and silver interlocking buckle can always be one of the favorite fashion accessories of the Ming Dynasty women.

\section{THE CULTURAL CONNOTATION OF THE MING DYNASTY GOLD AND SILVER INTERLOCKING BUCKLES}

\section{A. Intuitive expression of social aesthetics concept in the Ming Dynasty}

Through the Ming Dynasty gold and silver interlocking buckles, we can realize that people in the Ming Dynasty valued real life and loved auspicious patterns. Gold and silver ornaments inlaid with jewels had flowed from West Asia to China during the Sui and Tang Dynasties. At that time, the form of the ornaments still retained more exotic features. After the transition between Song and Yuan, the gold and silver ornaments of the Ming Dynasty preferred to express everyday things and placed a longing for a better life. For example, the "蝶采花(Butterflies and Flower)" theme interlocking buckles of the Ming Dynasty used "butterflies" to refer to "husband" and used "flower" to refer to "wife", implying a sweet and loving relationship between husband and wife; the "双银锭 (Double Silver Ingots)" theme interlocking buckles symbolized wealth by the images of silver ingots, expressing the Ming people's pursuit of rich life; the “芙 蓉捧寿 (Furong Flowers and Shou)"gold interlocking buckles, unearthed from Ding Ling, used the homonym "fushou(福寿)" of "fu(芙)" and "shou(寿)"to pray for its owner to live a long and healthy life; the patterns of sunflowers and lotuses in the Ming interlocking buckles became the symbol of "多子多孙(many children and grandchildren)", because of they can produce many seeds. These patterns on the Ming interlocking buckles are all related to the beautiful daily life, which is the embodiment of the Ming people's concept of paying attention to real life.

Also, through the Ming Dynasty gold and silver interlocking buckles, we can realize that the Ming people adored gold, silver and jewel materials. The interlocking buckle is a functional accessory in clothing, which can be made using cheaper and more common fabrics, but precious materials, such as gold, silver, jade and jewel, are often used in the Ming Dynasty interlocking buckles. For example, in the tomb of Zhu Youbin, the Ming Dynasty Prince of $\mathrm{Yi}$, in Jiangxi, two large size gold interlocking buckles of "蝶 
采 花 (Butterflies and Flower)" theme were discovered[4]. Each pair of them was inlaid with seventeen jewels, six on the button loop, one on the button, and ten on the two keepers, as shown in "Fig. $4 "$. In addition, in an ordinary person's tomb in the early Ming Dynasty, one pair of "蝶采葵花(Butterflies and Sunflower)" theme silver buckles were also discovered[5]. From the member of the royal family to the ordinary people, they all loved to use precious materials such as gold, silver, jade and jewel to make interlocking buckles, which is enough to show the Ming people's aesthetic concepts of adoring the gold, silver and jewel.

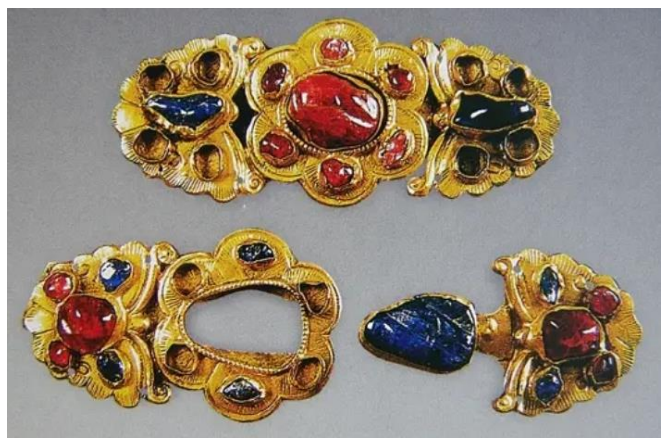

Fig. 4. The large size gold interlocking buckles of "蝶采花(Butterflies and Flower)" theme unearthed from the tomb of Zhu Youbin.

\section{B. Indirect proof of strong conspicuous consumption trends}

With the prosperity and development of the commodity economy, the consumption concept of the Ming people gradually have changed from "thrifty" in the early Ming Dynasty to "luxurious" in the middle and late Ming Dynasties. The number of gold and silver buckles that appeared in tombs in the middle and late Ming dynasties have increased tens of times compared to the beginning of the Ming dynasty, and this result was caused by the conspicuous consumption behavior of the Ming Dynasty society.

The American economist Thorstein Veblen once introduced the term "conspicuous consumption" in The Theory of the Leisure Class[6], which refers to the consumption activities that provide evidence of wealth and power to obtain or maintain respect and honor. He summed up the two main motivations for conspicuous consumption: one is invidious comparison, and the other is pecuniary emulation. Invidious comparison refers to the strata with higher wealth levels striving to differentiate themselves from the strata with lower wealth levels through conspicuous consumption. The aristocracy in the Ming Dynasty used gold, silver, jewels and other very expensive materials rather than cheaper fabrics, to make a lot of interlocking buckles. This is the conspicuous consumption motivated by invidious comparison, and its purpose is to prove their high wealth level, highlight their identity and status, and maintain their image of being in a higher class. For example, 71 pairs of gold and silver interlocking buckles were unearthed in the coffins of two Empress Wanli[7], and 105 pairs of gold and silver interlocking buckles were unearthed in the tomb of Ming Dynasty Princess of Yi[8]. These buckles were only the tip of the iceberg of their gold and silver funerary objects and the burial of such a large number of gold and silver vessels really proves the supreme power and high wealth level of the royal family. The conspicuous consumption also appeared in the lower stratum of the Ming Dynasty, motivated by pecuniary emulation. Pecuniary emulation refers to the stratum with lower wealth level trying to imitate the stratum with higher wealth level through conspicuous consumption in order to be considered as one of them. As described in the fourteenth chapter of Jin Ping Mei Ci Hua[9], on Pan Jinlian’s birthday:“只见潘金莲上穿了沉香色潞绸雁衔芦花样 对衿袄儿，白绫竖领，妆花眉子，溜金蜂赶菊钮扣儿...... ( Pan Jinlian was wearing a saffron-colored jacket of Lu-chou silk that opened down the middle and was decorated with a motif of wild geese holding bulrushes in their mouths. It had a stiff-standing white satin collar with purfled edging and gilt buttons that depicted honeybees rifling chrysanthemum blossoms...)" This is the conspicuous consumption in lower classes motivated by the pecuniary emulation. In the traditional hierarchy concept of "scholar, farmer, artisan and merchant", as the wife of a merchant, Pan Jinlian's social status should be low. But she implied the great wealth of her family through wearing gilded interlocking buckles in imitation of the upper class ladies, which aroused the envy of the other women. And it is the other women's envious gaze that can change Pan Jinlian's identity from a lowly merchant wife to an upper class lady.

After the middle Ming Dynasty, the extravagant ethos began to prevail, and the overstepping authority phenomenon in women's clothing is also more and more common. All of the above can prove that the conspicuous consumption trend is very strong in Ming society.

\section{The material medium to practice the concept of covering the body}

The stand collar with gold and silver interlocking buckles was one of the most distinctive and popular clothing structures in Ming Dynasty women's clothing. As shown in "Fig. 5", it is a portrait of a female in the Ming Dynasty wearing a stand-up collar with gold and silver interlocking buckles. Women in the Tang Dynasty loved to wear tube tops, which demonstrated the unrestrained thinking of the Tang women of exposing their bodies. In the Ming Dynasty, the stand collar with gold and silver interlocking buckles was commonly used in women's clothing, showing the conservative concept of the Ming women of covering 
their bodies. Women in the Ming Dynasty tended to cover their bodies partly for the strengthening of the “贞 节观(chastity view)”, and partly for the climate changes during the Ming Dynasty. And it is the gold and silver interlocking buckles that acted as the material medium for Ming Dynasty women to practice the concept of covering the body.

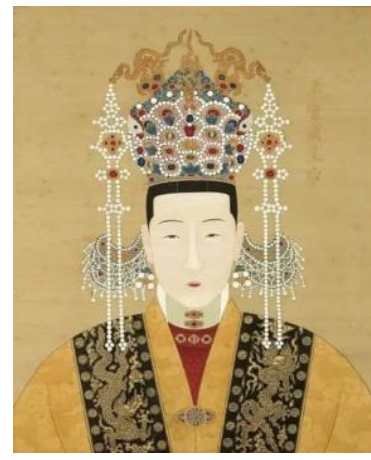

Fig. 5. The portrait of Empress Xiaojie in the Ming Dynasty wearing a stand-up collar with gold and silver interlocking buckles.

The performance of “贞节观 (chastity view)” in clothing was to hide the woman's body as much as possible with clothing. During the Southern Song Dynasty, when $\mathrm{Zhu} \mathrm{Xi}$ was the magistrate of Zhangzhou, Fujian, he had stipulated: “良家妇女出门，需 用蓝夏布一幅围罩头和颈项，以避免妇女抛头露面 (when gentlewomen went out, they needed a blue ramie cloth to mantle their heads and necks to prevent they from showing their faces in public)"[10]. In the Yuan Dynasty, Mrs.Ma in the Jie Fu Ma Shi Zhuan died of the ulcers on her breast, just because she insisted that she was Mr.Yang's widow and would rather die than be seen by men. It can be seen that the thought of women covering their body to avoid being seen by men had rooted in the hearts of the people because of the instruction of chastity on female that continued for hundreds of years during the Song and Yuan Dynasties. In the Ming Dynasty, the concept of woman keeping her chastity have been more prevailing because of the support of the law, and the idea of covering women's skin was naturally continued. Therefore, the stand collar with gold and silver interlocking buckles can remain in the Ming women's clothes.

In addition to the chastity view, climatic changes also prompted women in the Ming Dynasty tending to cover their bodies. During the Ming Dynasty, the average temperature in China was low. Using the structure of stand collar with interlocking buckles can make the traditional Chinese clothes wrap the body tighter and increase the warmth retention property of the clothing. Zhu Kezhen studied the temperature changes in ancient China according to the growth of vegetation and the freezing records of rivers, lakes and seas. His research showed that the annual average temperature during the Tang Dynasty was the highest in the past 1700 years and the annual average temperature during the Ming Dynasty was often two to three degrees lower than that during the Tang Dynasty[11]. These research results coincides exactly with the phenomenon that the Ming Dynasty clothes wrapped female's body tighter than the Tang Dynasty clothes, in order to increase the warmth retention property of the clothes.

The strengthening of the chastity concept and changes in climate and temperature all have prompted the Ming Dynasty women 's clothing towards the direction of covering the body. And the structure of stand collar with interlocking buckles has lasted for several hundred years, enduring and becoming an important element in Chinese style garment today.

\section{CONCLUSION}

As a unique accessory that appeared in Ming Dynasty women's clothing, the gold and silver interlocking buckle not only decorated the life of Ming Dynasty women, but also embodied the design aesthetics of Ming Dynasty utensils, and also witnessed the cultural changes of Ming Dynasty society. In the aspect of structure design, the gold and silver interlocking buckle in the Ming Dynasty adjusted the open-close structure on the basis of the structure of the fabric braid buckle to suit new material properties and improve its applicability. In the aspect of form design, the functional components of the gold and silver interlocking buckle are concealed by chic shapes to enhance its decorative nature. In a word, its overall design reflects the aesthetic concept of "exquisite and applicable". And, the popularity of gold and silver interlocking buckles in the Ming Dynasty became an intuitive manifestation of the Ming Dynasty society's aesthetic concept of paying attention to real life, loving auspicious patterns, and advocating gold and silver jewelry and provided indirect proof for the strong conspicuous consumption trends in Ming society. At the same time, it also acted the material medium for Ming Dynasty women to practice the concept of covering the body.

\section{References}

[1] Yang Zhishui, On "Butterfly Lingers Over the Flower" Design of Gold and Silver Jewelry in Ming Dynasty[J]. Collectors, 2008(06).(in Chinese)

[2] Wang Jiaqi, A Study on Decorative Metal Button of Female Apparels in Ming Dynasty[D]. Beijing Institute Of Fashion Technology, 2012.(in Chinese)

[3] Chen Fang, Beijing Institute Of Fashion Technology[J]. Journa of Nanjing Arts Institute(Fine Arts \& Design),2013(05).(in Chinese) 
[4] Jiangxi Provincial Museum, An Excavation Report of the Tomb of Zhu Youbin, Ming Dynasty Prince of Yi, in Nancheng, Jiangxi [J]. Cultural Relics, 1973(03).(in Chinese)

[5] Gao Zhenwei, Zhou Lining, An Excavation Report of Yejiadang Tomb of the Ming Dynasty in Jiangyin, Jiangsu[J]. Cultural Relics, 2009(08).(in Chinese)

[6] Thorstein Veblen, The Theory of the Leisure Class[M]. New York: Dover Publications, 1994.

[7] Institute of Archaeology, Chinese Academy of Social, Ding Ling[M]. Beijing: Cultural Relics Press, 1990.(in Chinese)

[8] Jiangxi Provincial Museum, Fan Wang's Tombs of the Ming Dynasty in Jiangxi [M]. Beijing: Cultural Relics Press, 2010.(in Chinese)

[9] Lanlingxiaoxiaosheng, Jin Ping Mei Ci Hua[M]. Beijing: People's Literature Publishing House, 2008.(in Chinese)

[10] Chen Baoliang. History of social life in the Ming Dynasty[M]. Beijing: China Social Sciences Press, 2004.(in Chinese)

[11] Zhu Kezhen, A preliminary study of climate change in China in the past five thousand years $[\mathrm{J}]$. Science in China,Ser.A, 1973(02): 168-189.(in Chinese) 